\title{
Effect of Multidisciplinary Approach in Diagnosis of Renal Sinus Fat Invasion in Renal Cell Cancer
}

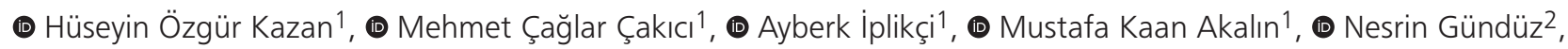 \\ ๑ Ramazan Gökhan Atış ${ }^{1}$, 1 Asıf Yıldııım ${ }^{1}$ \\ 1 Istanbul Medeniyet University, Göztepe Training and Research Hospital, Clinic of Urology, Istanbul, Turkey \\ 2 Istanbul Medeniyet University, Goztepe Training and Research Hospital, Clinic of Radiology, Istanbul, Turkey
}

\begin{abstract}
Objective: In order to make the most appropriate treatment decision for kidney masses, accurate radiological evaluation is vital. In this study, we aimed to discuss how would be the concordance between a multidisciplinary approach to renal masses and the histopathological outcome.

Materials and Methods: Between June 2017 and July 2019, 75 patients who were evaluated for complex renal tumors at the Council of Uroradiology and treated at our clinic were included in the study and their clinical-pathological data were examined. After radiological reporting, all patients were re-evaluated in this council consisting of 4 urologists and 2 radiologists.

Results: Forty-three patients underwent partial nephrectomy and 32 patients underwent radical nephrectomy. Malignant histopathology was present in $85.3 \%$ of patients. The mass was solid in 35 patients and was of cystic nature in 40 patients. Cystic and solid component assessments were similar in both groups. There was no difference between the two groups in terms of tumor node metastasis staging. Subgroup analysis showed that the correlation between radiological T3 and pathological T3 was not significant in radiology reports. However, this correlation was significant in the council assessment $(p<0.001)$.

Conclusion: As a result, the more important factor than the surgical method is which masses will be operated on and which masses will be monitored. Especially in complex patients, it is important to take this decision with a multidisciplinary approach and, if possible, with a team collaboration. Multidisciplinary evaluation has enabled us to achieve better results in determining the T3 stage, which is a factor that can change the surgical method and patient follow-up.

Keywords: Council, multidisciplinary, RCC, renal sinus invasion, uroradiology
\end{abstract}

\section{Introduction}

Renal cell cancer (RCC) accounts for $2-3 \%$ of all cancers. Along with improvements in imaging methods, there is an increase in incidental detection rates $(1,2)$. Accurate clinical staging at the time of diagnosis by computerized tomography (CT) or magnetic resonance imaging (MRI) is very important for providing information about primary tumor spread, venous involvement, locoregional lymph nodes, adrenal glands, surrounding solid organs and the status of the kidney of the opposite side (3). Clinical staging is done according to the current "tumor node metastasis" (TNM) staging. Tumor size, renal sinus invasion (RSI), venous invasion, renal capsule involvement, adrenal involvement, lymph node metastasis and distant metastasis are the parameters that are used in classification (4). In particular, RSI stands out as the basic step to see the local spread of the tumor, indicating that the tumor has entered the T3a stage in the TNM classification (5). In predicting RSI by imaging methods, the most important factor is the involvement of the pelvicalyceal system (6). In the treatment of T3a stage tumors, radical nephrectomy is the first option.

Patient management based on decisions which are made by multidisciplinary teams is becoming increasingly common worldwide. Studies have shown that, thanks to multidisciplinary decisions, significant changes are achieved in diagnosis/staging, patient management $(7,8)$ and even survival $(9,10,11)$. In this study, the predictive role of evaluation made primarily at the Council of Uroradiology ( $\mathrm{CoU}$ ) on RSI was aimed to be seen. Second, it was aimed to see the superiority of the CoU in distinguishing the benign-malignant or cystic-solid nature of the masses.

Cite this article as: Kazan HÖ, Çakıcı MÇ, İplikçi A, Akalın MK, Gündüz N, Atış RG, Yıldırım A. Bull Urooncol 2020;19(2):80-84 


\section{Materials and Methods}

There were 212 patients who had renal mass detected at the urology outpatient clinic and re-evaluated at the CoU. Seventy five out of 212 patients who underwent radical or partial nephrectomy were included in the study between June 2017 and July 2019. Ethics committee approval was obtained from our institution. Informed consent form was taken from all of the patients. Pathological assessment was treated as a gold standard diagnosis. The most of first radiological evaluation was performed by the "service procurement" radiologists and 10\% by our hospital's radiologist. Contrast enhanced CT or dynamic MRI imaging of the patients were evaluated for the second time at the $\mathrm{CoU}$, which consisted of 4 experienced urologists and 2 experienced radiologists (Figure 1).

In this council; the data of radiological dimensions, side, localization, clinical RSI, clinical $\mathrm{T}$ stage, cystic nature (if present) and Bosniak classification, lymph node involvement and distant metastasis of the tumor were kept regularly. The same informations in the radiology report were retrospectively scanned and added to the data. In this way, two groups were formed as the radiology report and the $\mathrm{CoU}$ report. The patient's demographic data, surgical methods used, pathological histological diagnosis, pathological RSI, T stage, and Fuhrmann

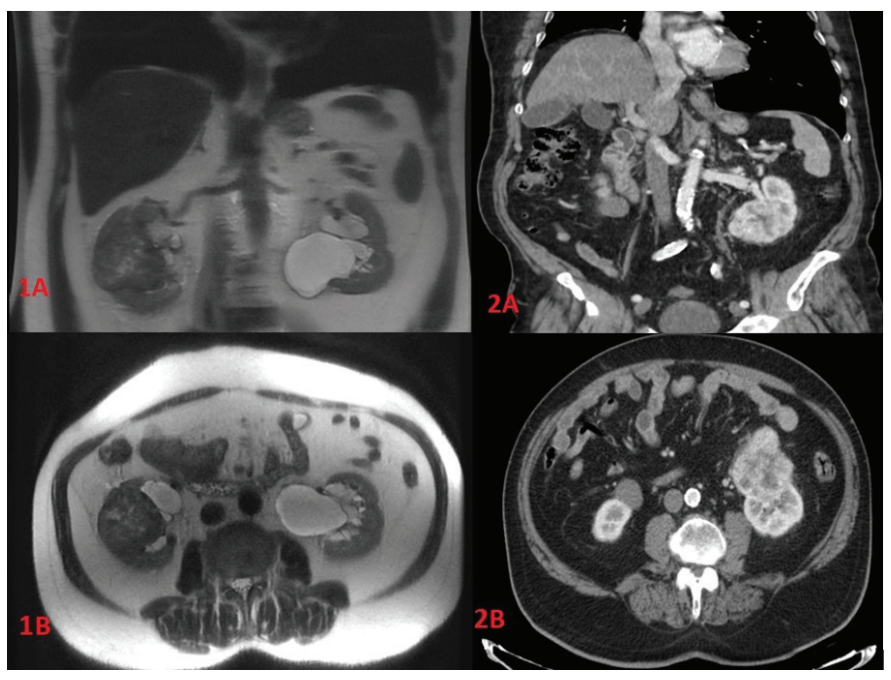

Figure 1. Renal masses with renal sinus invasion

1A: Coronal T2-weighted MR imaging, 1B: Axial T2-weighted MR imaging 2A: Coronal contrast enhanced $\mathrm{CT}$ imaging, 2B: Axial contrast enhanced $\mathrm{CT}$ imaging

MR: Magnetic resonance

CT: Computer tomography

Dynamic MR imaging of patient 1 who was a 63-year-old male: The mass in the mid-zone of the right kidney, which was $62 \mathrm{~mm}$ in size, was interpreted by the expert radiologist as $\mathrm{T} 1 \mathrm{~b}$ (group 1). It was interpreted as T3a in the $\mathrm{CoU}$ (group 2) and laparoscopic radical nephrectomy was performed. The pathology result was as follows: Clear cell RCC, Fuhrmann grade -1, stage T3a.

Contrast enhanced abdominal CT imaging of patient 2 who was a 77-year-old male: The mass in the lower pole of the left kidney, which was $90 \mathrm{~mm}$ in size, was interpreted by the expert radiologist as T2a (group 1). It was interpreted as T3a in the Council of Uroradiology (group 2) and laparoscopic radical nephrectomy was performed. The pathology result was as follows: Clear cell RCC, Fuhrmann grade -2 , stage T3a. grade were scanned. Two groups were compared in terms of diagnostic sensitivity, specificity, positive and negative predictive values and in terms of diagnostic compatibility inside the group (Figure 2: Patient selection diagram).

\section{Statistical Analysis}

Pearson correlation analysis was performed to determine the compatibility between the two groups and it was considered significant when the $p$ value was less than 0.05 .

\section{Results}

Forty three of the patients underwent partial nephrectomy (57.3\%) and 32 (42.7\%) underwent radical nephrectomy. Fifty nine of these patients (78.7\%) underwent laparoscopic surgery and 16 (21.3\%) underwent open surgery. 35 (46.7\%) of the tumors were solid and $40(53.7 \%)$ were of cystic nature. Pathological evaluation of the patients revealed malignant histopathology in 64 patients (85.3\%) and benign histopathology in 11 patients (14.7\%). The most common histology, clear cell RCC, was found in 45 (60\%) patients. Renal masses were most commonly found in the T1a stage in pathological diagnosis [30 patients (40\%)], while $13(17.3 \%)$ were found to be in the T3a stage (Table 1). Cystic and solid mass assessments and pathological findings were similar between both groups (Table 2). In predicting RSI, there was no correlation between radiological and pathological T3a in group 1, while there was correlation between them in group $2(p<0.0004)$. In the first group, sensitivity was $15.4 \%$, specificity was $93.9 \%$, positive predictive value was $33.3 \%$ and negative predictive value was $84.1 \%$ for RSI. In the second group, sensitivity was $61.5 \%$, specificity was $95.1 \%$, positive predictive value was $72.7 \%$ and negative predictive value was 92.2\% for RSI. When the correlation between the two groups was examined, the kappa coefficient $(\kappa)$ was found to be - 3.1 (Table-3).

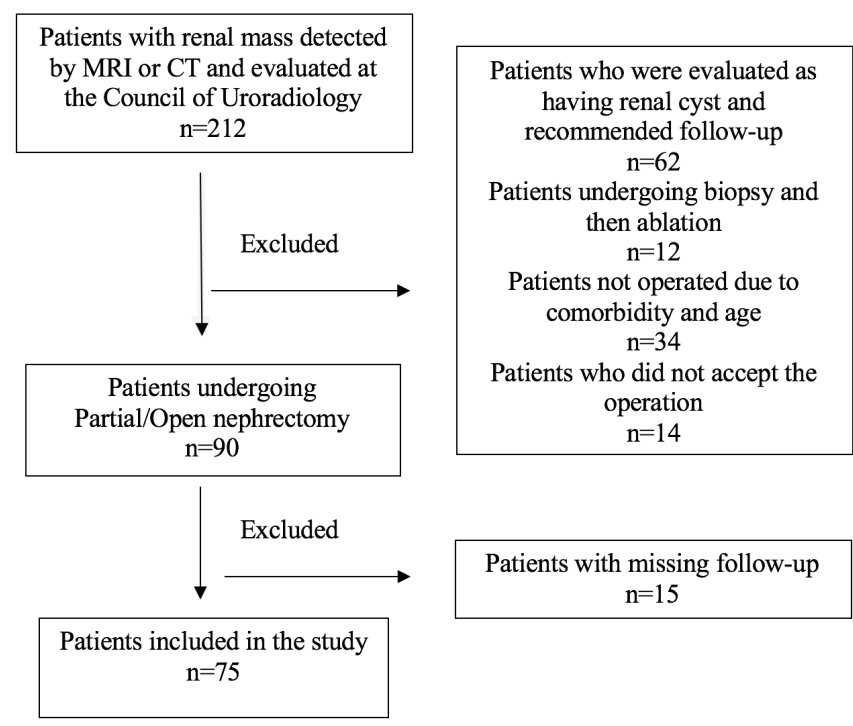

Figure 2. Patient selection diagram MRI: Magnetic resonance imaging, CT: Computer tomography, n: Number 


\begin{tabular}{|c|c|}
\hline Age, mean & $59.9 \pm 12.4(30-81)$ \\
\hline Radiological size, median (mm) & $42.0 \pm 28.1(18-190)$ \\
\hline Pathological size, median (mm) & $45 \pm 27.2(12-170)$ \\
\hline $\begin{array}{l}\text { Gender } \\
\text { Male/Female }\end{array}$ & $48 / 27$ \\
\hline Side, right/left & $39 / 36$ \\
\hline Localization, upper/middle/lower & $22 / 35 / 18$ \\
\hline Surgical technique, Open/Laparoscopic & $16 / 59$ \\
\hline $\begin{array}{l}\text { Surgical method } \\
\text { Partial Nephrectomy/Radical Nephrectomy }\end{array}$ & $43 / 32$ \\
\hline \multicolumn{2}{|l|}{ pT } \\
\hline T1a & 30 \\
\hline $\mathrm{T} 1 \mathrm{~b}$ & 16 \\
\hline T2a & 5 \\
\hline $\mathrm{T} 2 \mathrm{~b}$ & 2 \\
\hline T3a & 13 \\
\hline $\mathrm{T} 3 \mathrm{~b}$ & 1 \\
\hline \multicolumn{2}{|l|}{ Histological Type } \\
\hline Clear cell RCC & 45 \\
\hline Papillary type- 1 RCC & 2 \\
\hline Papillary type-2 RCC & 2 \\
\hline Chromophobe RCC & 9 \\
\hline Other RCC & 4 \\
\hline Oncocytoma & 4 \\
\hline Angiomyolipoma & 4 \\
\hline Other benign & 3 \\
\hline \multicolumn{2}{|l|}{ Fuhrmann Grade } \\
\hline Grade1 & 27 \\
\hline Grade2 & 17 \\
\hline Grade3 & 5 \\
\hline Grade4 & 1 \\
\hline Nonspecified & 25 \\
\hline
\end{tabular}

\section{Discussion}

For the diagnosis of RCC, CT or MRI are the appropriate diagnostic methods. In the interpretation of these images, differences in opinion among radiologists are often encountered. As a result of these differences; follow-up, decision of operation and operation types can change completely. Renal masses are basically divided into two parts as cystic and solid. Diagnosis of cystic complex masses can sometimes be more complicated. Sundi et al. (7) showed in their prospective study that sensitivity of CT was $36 \%$ and specificity of CT was $76 \%$, while sensitivity of MRI was $71 \%$ and specificity of MRI was $91 \%$ in complex cystic masses. The Bosniak classification, first defined in 1986, is also routinely used today for the classification of cystic masses (12). Yonguc et al. (13) showed that $77.6 \%$ of Bosniak type 3 and 4 cysts were histopathologically malignant. Similarly, in our study, the histopathology of $87.5 \%$ of cystic renal masses in the

\begin{tabular}{l}
\hline Table 2. Histopathological compliance of solid-cystic masses \\
\begin{tabular}{|l|l|l|l|}
\hline 1.Group: Radiologist-Pathology Compliance \\
\hline Radiological Evaluation & Histopathological Evaluation & Total \\
\hline & Malignant & Benign & \\
\hline Solid Renal Mass & $29(82.9 \%)$ & $6(17.1 \%)$ & 35 \\
\hline Cystic Renal Mass & $35(87.5 \%)$ & $5(12.5)$ & 40 \\
\hline & 64 & 11 & 75 \\
\hline
\end{tabular}
\end{tabular}

2.Group: Council of Uroradiology and Pathology Compliance

\begin{tabular}{|l|l|l|l|}
\hline $\begin{array}{l}\text { Council of Uroradiology } \\
\text { Evaluation }\end{array}$ & \multicolumn{2}{|l|}{$\begin{array}{l}\text { Histopathological } \\
\text { Evaluation }\end{array}$} & Total \\
\hline & Malignant & Benign & \\
\hline Solid Renal Mass & $31(83.8 \%)$ & $6(16.2 \%)$ & 37 \\
\hline Cystic Renal Mass & $33(86.8 \%)$ & $5(13.2 \%)$ & 38 \\
\hline & 64 & 11 & 75 \\
\hline
\end{tabular}

Table 3. Intergroup correlation in detecting renal sinus invasion 1.Group: Radiologist-pathology Compliance

\begin{tabular}{|l|l|l|l|}
\hline & \multicolumn{2}{|l|}{$\begin{array}{l}\text { Histopathological } \\
\text { Evaluation }\end{array}$} & Total \\
\hline Radiological Evaluation & RSI+ & RSI- & \\
\hline RSI+ & 2 & 4 & 6 \\
\hline RSI- & 11 & 58 & 69 \\
\hline & 13 & 62 & 75 \\
\hline
\end{tabular}

Pearson Correlation $\mathrm{p}=0.282$

2.Group: Council of Uroradiology and Pathology Compliance

\begin{tabular}{|l|l|l|l|}
\hline & \multicolumn{2}{|l|}{$\begin{array}{l}\text { Histopathological } \\
\text { Evaluation }\end{array}$} & Total \\
\hline Council of Uroradiology Evaluation & RSI+ & RSI- & \\
\hline RSI+ & 8 & 3 & 11 \\
\hline RSI- & 5 & 59 & 64 \\
\hline & 13 & 62 & 75 \\
\hline
\end{tabular}

Pearson Correlation $\mathrm{p}=0.0004$

\begin{tabular}{|l|l|l|}
\hline Detection of RSI with MRI or CT & & \\
\hline & Group-1 & Group-2 \\
\hline Sensitivity & $15.4 \%$ & $61.5 \%$ \\
\hline Specificity & $93.9 \%$ & $95.1 \%$ \\
\hline Positive Predictive Value & $33.3 \%$ & $72.7 \%$ \\
\hline Negative Predictive Value & $84.1 \%$ & $92.2 \%$ \\
\hline
\end{tabular}

RSI: Renal sinus invasion, MRI: Magnetic resonance image,

CT: Computer tomography

first group and $86.8 \%$ of cystic renal masses in the second group were malignant. On the other hand, differences in opinion in the diagnosis of Bosniak grade 2, 2F and 3 cysts are more often 
encountered than Bosniak grade 1 and 4 cysts. In both studies, it was observed that the alignment between radiologists was moderate in Bosniak 2-3 cysts $(14,15)$. In our study, 40 out of 75 patients $(53.3 \%)$ were evaluated as having cystic renal mass in group 1, while 38 out of 75 patients $(50.7 \%)$ were evaluated as having cystic renal mass in group 2. Malignant characteristics of cystic masses were also found to be similar in both groups ( $87.5 \%$ vs. $86.8 \%)$.

In patients undergoing nephrectomy, detection of RSI is defined as pT3a according to TNM staging. According to many studies, positivity of RSI is associated with poor prognosis. Prediagnosis of these patients is possible with preoperative imaging. Thompson et al. (16) indicated that the patients who underwent radical nephrectomy, were shown as having pT1 stage and died in follow-up had more RSI. Of the 577 patients identified as having PT1 stage disease, 49 died in 17-year follow-up. Among these patients, original specimens of 33 were re-examined and $14(42 \%)$ of these patients were found to have RSI. García Marchinena et al. (17) reported that RSI was associated with poor prognosis. Bedke et al. (18) showed that perinephric and renal sinus fat invasion was identified as a poor prognostic marker in their study involving 106 patients with T3a tumors. Five-year cancer-specific survival was indicated as $31 \%$ when both were positive. Therefore, prior recognition of RSI is very important in the follow-up of the disease. Bolster et al. (19) showed that tumor size, location, irregular tumor boundaries and invasion of the pelvic system were the most important factors in determining RSI during the preoperative period.

In our study, it was observed that the point at which the two groups diverged was RSI. When only the radiology report was taken; the sensitivity of detection of RSI was $15.4 \%$, specificity was $93.9 \%$, positive predictive value was $33.3 \%$, negative predictive value was $84.1 \%$ and there was no correlation between the pathologist and the radiologist in the correlation analysis. On the other hand; sensitivity was $61.5 \%$, specificity was $95.1 \%$, positive predictive value was $72.7 \%$ and negative predictive value was $92.2 \%$ in group 2 and there was correlation between the pathologist and the radiologist. When the Kappa value was calculated to measure the alignment between the two groups, it was calculated as - 3.1, and this showed that there was a serious disagreement between the two groups. Renard et al. (20) evaluated the detection of T3a renal masses by multidetector CT and showed that the alignment between two radiologists was poor. Bolster et al. (19) observed that there was a moderate level of alignment between two radiologists in determining RSI. Taking this decision in the CoU affected the surgeon's decision of operation and had a primary effect on partial and radical nephrectomy decision in patients with T3a tumor. Radical nephrectomy is also recommended for T3a tumors except for very rare publications in the literature (21).

Many previous studies have indicated that multidisciplinary approach leads the management of patients in a critical way. Kurpad et al. (22) showed that diagnosis or treatment of $38 \%$ of 269 patients with urological malignancies changed, especially in bladder and kidney cancer, when they were evaluated multidisciplinarily. Pillay et al. (23) evaluated the effects of decision making following a multidisciplinary approach on diagnosis, staging, patient management and patient survival in oncology patients in the systematic review of 27 studies. This review showed that between $4 \%$ and $45 \%$ of patients had a change in diagnosis. It was determined that patients who were evaluated as multidisciplinary received treatments more appropriate to the current guidelines, had more appropriate staging, and received neoadjuvant and adjuvant therapy more frequently.

\section{Study Limitations}

This study is the first to demonstrate the importance of multidisciplinary approach in predicting RSI. The limitations of the study included that it was retrospective and that it was conducted with relatively few patients. The lack of patients' survival data could be demonstrated among the limitations. The lack of information about which radiologist in the service procurement evaluated $\mathrm{CT}$ and the experience of this radiologist, the lack of data on whether there was difference between CT and MRI could be seen as limitations of the study.

\section{Conclusion}

The multidisciplinary approach to detecting RSI has higher sensitivity, specificity, positive and negative predictive values than radiology reporting. In terms of RSI, the surgeon's re-evaluation of the imaging with the radiology team during the preoperative period will significanty affect the approach to these patients in terms of decision of radical/partial nephrectomy.

\section{Acknowledgements}

Publication: This study was presented in the $9^{\text {th }}$ Eurasian Urooncology Congress on October 16-20 in 2019 in Athence, Greece.

Contribution: There is not any contributors who may not be listed as authors.

Conflict of Interest: No conflict of interest was declared by the authors.

Financial Disclosure: The authors declared that this study received no financial support.

\section{Ethics}

Ethics Committee Approval: The study was approved by İstanbul Medeniyet University, Göztepe Training and Research Hospital Committee (approval no: 2020/0198)

Informed Consent: Informed consent form was taken from all of the patients.

Peer-review: Externally peer-reviewed.

\section{Authorship Contributions}

Concept: H.Ö.K., M.Ç.Ç., A.Y., Design: H.Ö.K., M.Ç.Ç., Data Collection or Processing: H.Ö.K., M.Ç.Ç., A.İ., M.K.A., Analysis or Interpretation: A.Y., R.G.A., N.G., Literature Search: N.G., Writing: H.Ö.K., M.Ç.Ç.

\section{Referanslar}

1. King SC, Pollack LA, Li J, et al. Continued increase in incidence of renal cell carcinoma, especially in young patients and high grade disease: United States 2001 to 2010. J Urol 2014;1665-1670. 
2. Kato M, Suzuki T, Suzuki $Y$, et al. Natural history of small renal cell carcinoma: evaluation of growth rate, histological grade, cell proliferation and apoptosis. J Urol, 2004;172:863-866.

3. Yamashita Y, Ariyoshi A, Sakamoto K, et al. The therapeutic value of lymph node dissection for renal cell carcinoma. Nishinihon J Urol 1989:777.

4. Brierley JD, Gospodariwicz M, Wittekind C, et al. TNM classification of malignant tumors. UICC International Union Against Cancer. 7th edn. (eds). Wiley-Blackwell, 2009.

5. Bonsib SM. The renal sinus is the principal invasive pathway: A prospective study of 100 renal cell carcinomas. Am J Surg Pathol 2004;28:1594-1600.

6. Tsili AC, Goussia AC, Baltogiannis D, et al. Perirenal fat invasion on renal cell carcinoma: evaluation with multidetector computed tomography-multivariate analysis. J Comput Assist Tomogr 2013;37:450-457.

7. Sundi D, Cohen JE, Cole AP, et al. Establishment of a new prostate cancer multidisciplinary clinic: format and initial experience. Prostate 2015;75:191-199.

8. Korman H, Lanni T, Shah C, et al. Impact of a prostate multidisciplinary clinic program on patient treatment decisions and on adherence to NCCN guidelines: the William Beaumont Hospital experience. Am J Clin Oncol 2013;20:778-784.

9. Yopp A, Mansour J, Beg M et al. Establishment of a multidisciplinary hepatocellular carcinoma clinic is associated with improved clinical outcome. Ann Surg Oncol 2014;21:1287-1295.

10. Lordan JT, Karanjia ND, Quiney N et al. A 10-year study of outcome following hepatic resection for colorectal liver metastases: the effect of evaluation in a multidisciplinary team setting. Eur J Surg Oncol 2009;35:302-306.

11. Stephens MR, Lewis WG, Brewster AE et al. Multidisciplinary team management is associated with improved outcomes after surgery for esophageal. Dis Esophagus 2006;19:164-171.

12. Koga S, Nishikido M, Inuzuka S, et al. An evaluation of Bosniak's radiological classification of cystic renal masses. BJU Int 2000;86:607-609.
13. Yonguç T, Bolat D, Aydoğdu Ö, et al. Clinical and Pathological Features of Bosniak Type III and Type IV Renal Cysts: A Six Year Experience. Bull Urooncol 2015;14:174-177.

14. Benjaminov O, Atri M, O'Malley M. et al. Enhancing component on CT to predict malignancy in cystic renal masses and interobserver agreement of different CT features. American Journal of Roentgenology 2006;186:665-672.

15. Siegel CL, McFarland EG, Brink JA, et al. CT of cystic renal masses: Analysis of diagnostic performance and interobserver variation. Am J Roentgenol 1997;169:813-818.

16. Thompson RH, Blute ML, Krambeck AE, et al. Patients with pT1 renal cell carcinoma who die from disease after nephrectomy may have unrecognized renal sinus fat invasion. Am J Surg Pathol 2007;31:1089-1093.

17. Garcia Marchinena P, Tobia I, Abreu D, et al. Prognostic value of perirenal and/or sinus fat infiltration in patients with pT3a renal cell carcinoma: A multicentre cohort study. LARCG Group. Actas Urol Esp. 2019;495-502.

18. Bedke J, Buse S, Pritsch $M$, et al. Perinephric and renal sinus fat infiltration in $\mathrm{pT} 3 \mathrm{a}$ renal cell carcinoma: Possible prognostic differences. BJU Int 2009;103:1349.

19. Bolster F, Durcan L, Barrett C, et al. Renal cell carcinoma: Accuracy of multidetector computed tomography in the assessment of renal sinus fat invasion. J Comput Assist Tomogr. 2016;40:851-815.

20. Renard AS, Nedelcu C, Paisant A, et al. Is multidetector CT-scan able to detect T3a renal tumor before surgery? Scand J Urol 2019;1-6.

21. Mouracade P, Dagenais J, Chavali JS, et al. Perinephric and Sinus Fat Invasion in Stage pT3a Tumors Managed by Partial Nephrectomy. Clin Genitourin Cancer 2018;16:e1077-1082.

22. Kurpad R, Kim W, Rathmell WK, et al. A multidisciplinary approach to the management of urologic malignancies: does it influence diagnostic and treatment decisions? Urol Oncol 2011;29:378-382.

23. Pillay B, Wootten AC, Crowe $\mathrm{H}$, et al. The impact of multidisciplinary team meetings on patient assessment, management and outcomes in oncology settings: A systematic review of the literature. Cancer Treat Rev 2016;42:56-72. 